\title{
Mindful Deviation through Combining Causation and Effectuation: A Design Theory-Based Study of Technology Entrepreneurship
}

\author{
Marine Agogué, Mats Lundqvist and \\ Karen Williams Middleton
}

Technology entrepreneurship can be seen as building upon, while also deviating from, technological paths. Such deviation has primarily been described as singular events where individuals with prior knowledge discover a new opportunity. In this article, we will instead study deviation as a process of collective decision making, seen more as something mindful than singular. The purpose is to explore mindful deviation as decision making by nascent technology entrepreneurs as they conceptualize an early platform technology. Based on case assignments undertaken by 13 teams in a venture creation programme, C-K design theory is used to trace how nascent technology entrepreneurs in action combine causal and effectual decisionmaking logics. Individually answered questionnaires also offered insights into how the entrepreneurs perceived their decision making in hindsight. The findings break with our received wisdom around how opportunities are recognized as well as how effectual and causal logics occur. As a result, mindful deviation through combinations of effectual and causal logic is suggested as a means to understand early-stage technology entrepreneurship.

\section{Introduction}

U nderstanding how to draw from, but also deviate from, the larger technological setting is central in technology entrepreneurship (Shane \& Venkataraman, 2003; Bailetti, 2012; Garud, Gehman \& Giuliani, 2014; Ratinho, Harms \& Walsh, 2015). Technology entrepreneurship is therefore seen as more dependent upon technological paths compared to entrepreneurship in general (Garud \& Karnøe, 2003). Technology entrepreneurship is also associated with more deviating and path-breaking behaviour when compared to technological innovation in general (Garud \& Karnøe, 2001b). In the path dependency literature, deviation is mostly depicted as a discrete or abrupt event, for example a singular event of discovery (Sydow, Schreyögg \& Koch,
2009). The concept of mindful deviation (Garud \& Karnøe, 2001b) opens up for a perspective in which articulated decision making, rather than singular accidental events, explains how path breaking occurs. However, the field currently lacks means to effectively trace and interpret early entrepreneurial decision-making processes that lead to path breaking.

In this article, we investigate technology entrepreneurship as mindful deviation from technological paths. Nascent technology entrepreneurs are asked to graphically illustrate their conceptualization of a technology platform using a design theory called C-K theory. The diagrams are interpreted as indicating the occurrence of causal and effectual decision making (Sarasvathy, 2001), as are also the results from a questionnaire measuring 
perceived use of these logics in hindsight by the entrepreneurs.

C-K theory offers a graphical representation of design activities through diagrams (Hatchuel, Le Masson \& Weil, 2004; Agogué et al., 2014). These diagrams include the two spaces, concept-space (hereafter C-space) and knowledge-space (hereafter K-space), and illustrate the gradual expansion of these spaces as well as how new concept attributes sometimes stimulate the search for new knowledge and vice versa. K-space emphasizes things we know are identifiable as true or false and seen as readily accessible, such as knowledge manifested in patents. C-space represent concepts, which cannot be identified as either true or false, but are more or less desirable, such as an 'intelligent car'. A C-K diagram is thus a tool that can be used to represent an early design process in which attributes for a future product are determined (see Figure 1). In this study, C-K diagrams are interpreted into occurrence of causal or effectual decision making based upon a generated framework.

Effectuation has been identified as a decision-making logic used by experienced entrepreneurs during situations of uncertainty, in collaboration with committed stakeholders (Read \& Sarasvathy, 2005; Sarasvathy, 2008; Dew et al., 2009). Effectuation enables entrepreneurs to co-create new and unanticipated effects from known means (Read \& Sarasvathy,
2005; Wiltbank et al., 2006; Sarasvathy, 2008), and is a complementary alternative to causation. Causation involves processes used to select and/or predict actions towards specifically set goals - a predictive, and thus more consequential, decision-making logic (Sarasvathy, 2001).

Causal and effectual decision making have mainly been explored conceptually or empirically in hindsight (Perry, Chandler \& Markova, 2011). Therefore, we know less about the actual causal- and effectual-based behaviour of entrepreneurs (Sarasvathy \& Venkataraman, 2011; Fisher, 2012; Nielsen \& Lassen, 2012). This motivates an explorative use of C-K theory to detect such decision making in real time. Furthermore, by also measuring in hindsight perceptions of decision-making logics regarding to the same situation, comparison to previous studies can be made (Chandler et al., 2011; Perry, Chandler \& Markova, 2011). Taken together, the purpose of this article is to explore mindful deviation in technology entrepreneurship as decision making combining effectual and causal logics, using both real-time (C-K diagrams) and hindsight (questionnaire) methods.

The article is structured as follows. First of all, we propose an analytical framework for tracing conscious entrepreneurial decision making based on causal and effectual logics through application of C-K theory (Hatchuel \&

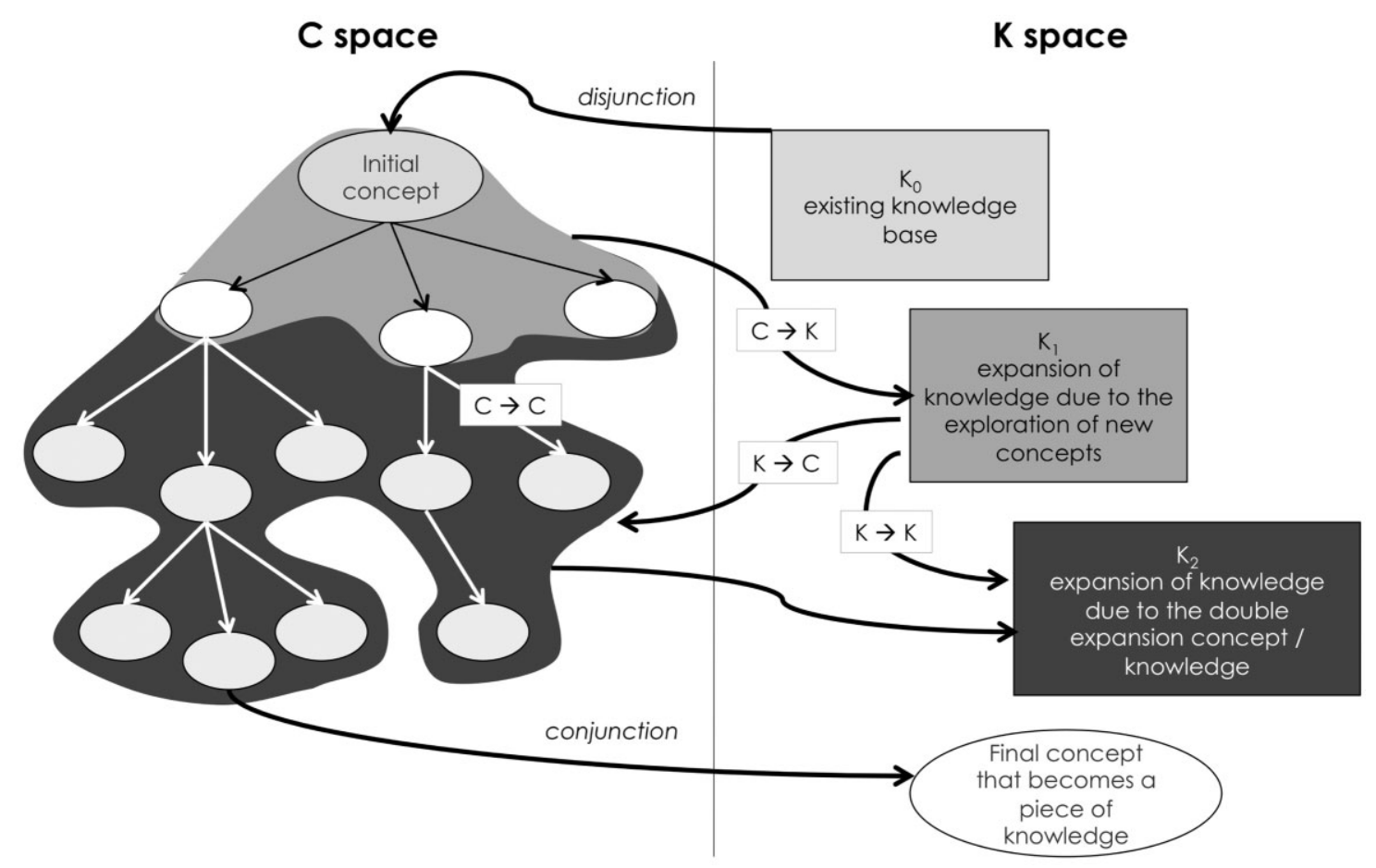

Figure 1. Principles of C-K Theory Displayed in a C-K Diagram 
Weil, 2009). We show that the different principles of causation and effectuation can be derived from steps illustrated through C-K diagrams. We apply the framework to a study of 13 teams of nascent technology entrepreneurs in a venture creation programme (Van Burg et al., 2008; Lackéus \& Williams Middleton, 2015) as they are asked to explore (and add to) a patented technology platform. The discussion focuses on how the findings break with existing understandings of opportunity recognition, as well as how effectual and causal logics occur. Finally, limitations of the current study and future research needs are discussed.

\section{Literature Review}

To explore decision making as a way of understanding deviation and path breaking in technology entrepreneurship, we review literature addressing mindful deviation. We go on to link this literature to developments around entrepreneurial decision making through causation and effectuation. Finally C-K diagrams are introduced as well as how such diagrams can be interpreted to identify occurrence of causal and effectual logics.

\section{Mindful Deviation in Technology Entrepreneurship}

Recent research has investigated processes leading to the creation of new opportunities that deviate from established technological paths (Marvel \& Lumpkin, 2007; Doganova \& Eyquem-Renault, 2009; Beckman et al., 2012). Such processes tend to be studied from a social perspective: for instance, Doganova and Eyquem-Renault (2009) explore how technology entrepreneurs use business models as devices to interact with potential stakeholders and explore different market opportunities. Focusing on reasoning processes, Marvel and Lumpkin (2007) describe the cognitive mechanisms technology entrepreneurs mobilize to shape innovation radicalness. This is done by stressing the role of different types of knowledge in the construction of radical innovation. A challenge for the technology entrepreneur is to draw from technological paths while also becoming path-breaking and deviating towards new opportunities. The current dominant view is that entrepreneurial opportunities stem from discovery rather than from deliberate processes (Shane \& Venkataraman, 2000). Such essentially 'singular' events of discovery have been related to persons either with more prior knowledge in an area (Shane, 2000) or having strong pattern-recognition capabilities (Baron, 2006).
Mindful deviation has been defined as technology entrepreneurs articulating and creating relevance around opportunities that are path breaking (Garud \& Karnøe, 2001b, 2003). In emphasizing articulation and relevance, it is possible to relate the concept to a collective decision making involving others to be on board or at least convinced about a deviation. Mindful deviation, to our knowledge, has not been used to empirically study initial identification of a new concept or opportunity. If mindfulness, in terms of articulated decision making, could be conceptualized and empirically traced, then early-stage path-breaking behaviours could be demystified, be made more manageable, and be seen as less associated with individual creativity or capabilities only. Before introducing a means for tracing early-stage decision making, we first need theory to address decision making.

\section{Principles of Causation and Effectuation}

The two decision-making logics of effectuation and causation can help us understand the process of mindful deviation. We have already introduced causation as a commonly applied logic in which a course of action is based upon a predetermined goal, including the marshalling of resources to achieve that goal (Sarasvathy, 2001, 2008). Causation operates on a set of principles: set a goal and focus on what ought to be done to achieve that goal, pursue the best opportunities towards achieving the goal, surprises or deviations from the goal should be prevented whenever possible, set up contractual relationships that facilitate achieving the goal, and predict the future in order to control it. Causation is seen as a viable decision-making logic under known or knowable conditions (Sarasvathy, 2001).

Effectuation is the logic utilized to make decisions based on readily available means, rather than on predetermined goals (Sarasvathy, 2001, 2008). Effectuation argues that (expert) entrepreneurs develop a decision-making capacity that allows them to explore new opportunities jointly with committed stakeholders, particularly in situations of uncertainty or unknowable future consequences. Researchers claim that (expert) entrepreneurs use their available means to develop opportunities based on guesses about uncertain future preferences (Sarasvathy, 2001, 2008; Read \& Sarasvathy, 2005; Sarasvathy \& Dew, 2005; Dew et al., 2009; Read et al., 2011). Thus, effectual decision making is seen as more viable than other decision-making logics when operating in uncertain and unpredictable circumstances, because it emphasizes the entrepreneur's own action as the basis for control and progress (Sarasvathy \& Dew, 2005). 
Effectuation is proposed as an alternative and complementary approach (not a replacement) to causation (Sarasvathy, 2001; Sarasvathy et al., 2008; Chandler et al., 2011). Thus, mirroring causation, effectuation also builds upon five core principles: start with a given set of means focusing on what can be done, risk no more than you can afford to lose, leverage contingencies, form alliances with committed stakeholders, and focus on the things you can control to shape the future when it is seen as unpredictable (Sarasvathy, 2008; Read et al., 2011). The principles of causation and effectuation are summarized in Table 1.

Just as mindful deviation emphasizes human actions of articulation and relevance, effectuation also positions human action centrally but as the 'predominant factor shaping the future' (Sarasvathy, 2008, p. 87). However, methods to detect effectual logic in action remains underdeveloped (Obrecht, 2011; Fisher, 2012). Causation requires one to make sense of a linear process of aligning resources towards a pre-defined goal. Detecting effectuation implies highlighting the expansiveness of the process, i.e. the possible different paths that entrepreneurs explore (Sarasvathy, 2003; Sarasvathy et al., 2008). One way to model decision making is to model the diversity of the explorative activities that an entrepreneur undertakes. These activities would include the conceptual ideas an entrepreneur explores but chooses not to build upon, the knowledge an entrepreneur both

Table 1. Interpretation of Causation and Effectuation in C-K Theory Framework

Description

\section{Effectual principles}

\section{Focus on optimal scenarios and reaching pre-set goals \\ Start with given goals \\ Calculate upside potential and pursue the best opportunity \\ Set up transactional relationships with customers and suppliers \\ Prevent as much as possible negative contingencies or unexpected events that affect the desired goal \\ The future can be readily predicted \\ Causal principles}

Focus on doing the doable and pushing it forward

Start with given means: who you are, what you know and who you know

Calculate downside potential, and risk no more than you can afford to lose

Build your market together with trusted critical stakeholders

Any contingency (even negative) can trigger imaginative rethinking of possibilities and transformation of targets

Using strategies for creating a future
Interpretation in C-K theory framework 
starts with and acquires, and the resources an entrepreneur mobilizes in his/her network of stakeholders. These actions of entrepreneurs can be seen as a design process. This is why $\mathrm{C}-\mathrm{K}$ design theory is used here to detect occurrence of decision making.

\section{C-K Theory}

$\mathrm{C}-\mathrm{K}$ theory is a theory of design, based on empirical studies of more or less radical development of technology-based products (Hooge, Agogué \& Gillier, 2012; Hatchuel, Weil \& Le Masson, 2013). In C-K theory, design is defined as the process of generating new things (Hatchuel, Weil \& Le Masson, 2013; Chakrabarti \& Blessing, 2014), and involves both a specific mode of reasoning (Simon, 1996), and a collective process that enables individuals and/or organizations to propose innovative products or services, and new business models or strategies (Hatchuel, Le Masson \& Weil, 2005). C-K theory relies on modelling expansion, understood as the extension of existing definitions of objects in diverse directions (Hatchuel \& Weil, 2009) with the objective to both explore and substantiate new ideas. Among the diverse theoretical frameworks proposed in the field of design, C-K theory (Hatchuel \& Weil, 2009) holds specific properties (Sharif Ullah, Rashid \& Tamaki, 2012) that can be of particular interest towards further understanding of causation and effectuation.

$\mathrm{C}-\mathrm{K}$ theory establishes distinction between two spaces: a space of knowledge (K-space), defined as a set of propositions that all have a logical status and thus are recognized as either true or false; and a space of concepts (C-space) defined as a set of undecidable propositions propositions that have no logical status and thus cannot be proven as either true or false. The K-space maps all the knowledge necessary to understand and develop an idea into action. The C-space is a tree-structure of undecidable propositions, where each node of the tree corresponds to a partition (in the mathematical sense) of the mother concept into several sub-concepts (see Figure 1). Thus, the C-space maps explorable alternatives, but alternatives which require new knowledge in order to be put into action. C-K theory links the exploration of different alternatives (labelled as 'concepts' and positioned in the C-space) to the resources required to address and develop these potential ideas by mapping the knowledge associated to each alternative in the $\mathrm{K}$-space. Through this modelling process, C-K theory can illustrate application of different types of decision making. Mapping in the C-space allows for discussion associated to effectual logic, where means (existing knowledge/resources) are used to explore and expand on new concepts. The convergence on a particular goal, use of causal logic, is done by bringing together different sets of knowledge, modelled as a single path in the $\mathrm{C}$-space with the knowledge associated to each attribute that constitutes the idea at the core of the design process. C-K theory allows for parallel exploration of several ideas as different paths in the C-space, as well as surprising discovery of new areas of knowledge.

Graphical representation of design activities is possible through a $\mathrm{C}-\mathrm{K}$ theory-based tool called a C-K diagram (Agogué et al., 2014). A $\mathrm{C}-\mathrm{K}$ diagram illustratively maps the C-space and the K-space, representing the modelling expansion of these two spaces, and distinction of differentiating alternatives. It is therefore a tool that can be used to model a design process, including the status, at a precise time, of the available knowledge and various attributes added to the initial concept during the design process. A C-K diagram can be applied in different ways, but it is particularly useful in allowing representations of a design process and thus support an enriched discussion with other actors (for an extensive list of applications, see, e.g., Hooge, Agogué \& Gillier, 2012). $\mathrm{C}-\mathrm{K}$ theory is unique in that it has focused on specific design processes that lead to disruptive ideas (for an extensive literature review on C-K theory, see Agogué \& Kazakçi, 2014). Thus, a C-K diagram can be seen as a useful and unique tool for studying mindful deviation in early-stage idea development, as it accounts for diverse paths of exploration and the associated necessary learning, through knowledge acquisition, in order to make concepts actionable. Moreover, by using a C-K diagram, an individual or a group can generate discussions covering several dimensions: what knowledge or attributes have been deepened, what are the alternatives that have been discussed and/or chosen, what design paths remain unexplored and, eventually, which path to pursue (Agogué et al., 2014).

\section{Using C-K Diagrams to Detect Causation/Effectuation: An Analytical Framework}

Building on mindful deviation, causation/ effectuation and C-K theory, we propose an analytical framework to trace causal and effectual decision making using C-K diagrams (summarized in Table 1), in a vein similar to previous work matching causation and effectuation to $R \& D$ context dimensions (see, e.g., Brettel et al., 2012, p. 169).

In Table 1, causation, in general terms, involves the development of optimal scenarios and reaching preset goals. This can 
be interpreted as determining a defined goal for the development of an idea, and then explicitly identifying the knowledge required to reach that goal, including identifying how to obtain the knowledge required. Knowledge identification emphasizes validating what is known because the outcome should be predictable. Anticipating expected returns (third row in Table 1) equates to exploring one linear path (alternative) in the C-space, identifying the knowledge associated to this alternative in the K-space, and evaluating the value and the associated risks of this single path. In this sense, a causal process would appear as a single path in the C-space that stimulates the gathering of relevant pieces of knowledge, such as potential economic gains or strategies to face potential risks.

The focus on the competitive landscape involved in the causal decision making (fourth row in Table 1) can be seen as focusing on the paths that already exist and that are currently explored by different stakeholders. Exploitation of these existing known paths triggers positioning of the chosen path in a more strategic way, stressing the similarities and differences between the chosen path and paths explored by competitors, with the aim of gaining competitive advantage. Avoiding environmental contingencies means avoiding surprises, such as the emergence of disruptive concepts (fifth row in Table 1). A C-K diagram of a causal decision-making process would not display new surprising paths in the C-space, or expansion in the knowledge space. Finally, the predictive principle in a causal logic refers to the control and anticipation of all known possibilities, requiring an extensive mapping of the K-space with much overlap between the combined pieces of knowledge, in order to consider the decision-making process as a closed one, where all the possible events are anticipated.

The effectuation principles are presented in rows seven through eleven in Table 1 . The first principle states that one should start with the set of means readily available, which in a C-K diagram involves explicitly mapping the existing knowledge around the initial idea. A C-K diagram including effectuation develops in the C-space to display multiple partitions leading to several alternative paths which are achievable based upon collected knowledge, without predetermining which path should be selected as the outcome of the process.

Focusing on affordable loss (row eight in Table 1) can be seen as evaluating multiple paths, as well as the ability to shift from one path to another. In a C-K diagram this is illustrated through links between the C-space and the $\mathrm{K}$-space when one path appears as a dead end. Referencing back to the knowledge and expertise associated with the dead-end path can allow for identifying new value for another partition (new pathway). The first two effectuation principles underline possible gains from experimenting with as many strategies as possible within the given limited means available (Read et al., 2011).

Strategic alliances (row nine in Table 1) can be traced through expansion in both the $\mathrm{C}$-space and the $\mathrm{K}$-space relative to the competencies and resources of associated stakeholders, including interpretation of value propositions not only for the entrepreneur him/herself, but also for the network of stakeholders. This increases value options across the network of actors, and grants robustness to the design process of the entrepreneur. Leveraging the environmental contingencies (row ten in Table 1) can be understood as exploring but also exploiting surprises in the C-space. Typically, unexpected disruptive concepts that challenge existing representations of the given problem are appreciated (rather than problematic), as they are seen as opportunities to explore further unpredicted value. Reaction to this unpredictability, through application of C-K theory, addresses building alternatives that are able to accommodate variations of context. As a result, such alternatives can be seen to be adaptable within a dynamic environment, and thus are not predetermined based on a need to execute planning.

The framework to identify use of causal and effectual decision making through C-K diagrams is exemplified in Figure 2 and 3. Figure 2 illustrates how path trajectories built mainly on use of causal logic would appear in a C-K diagram. Existent knowledge is used to establish a concept in the C-space which is to follow a predetermined goal. The singular partition and expansion shows development of the concept along the predetermined path. New knowledge to be acquired in the K-space is based upon the set goal.

Figure 3 shows how a C-K diagram may look if effectual logic is utilized while developing a new idea. The existing knowledge in the K-space is used to develop a concept that has multiple partitions. Some partitions are more obvious while others are more surprising, but all generate the need to determine new knowledge in the K-space. The new knowledge may be expansion of the initial existing knowledge, or it may be knowledge or resources associated to stakeholders. The final path for development of the idea is not predetermined, but rather emerges from the options generated through linking the $\mathrm{C}$ and $\mathrm{K}$ spaces. 
C-space K-space

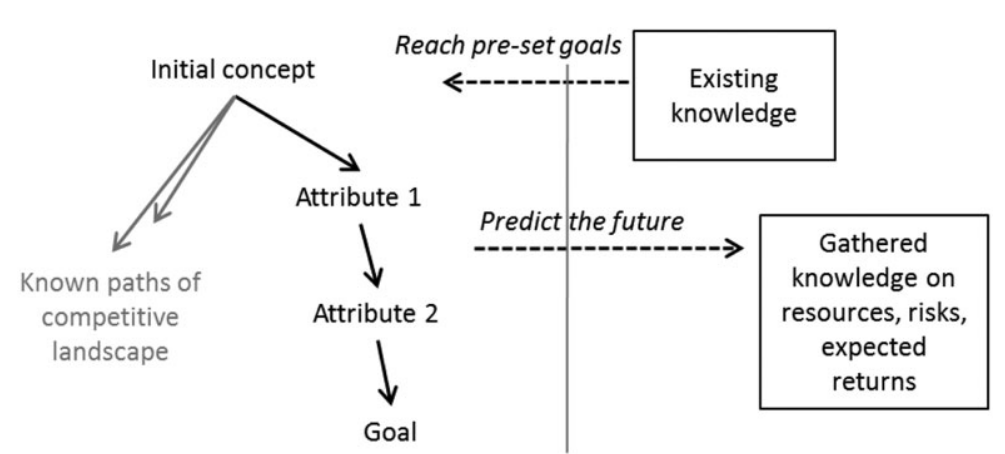

Figure 2. Causation through C-K Theory

C-space K-space

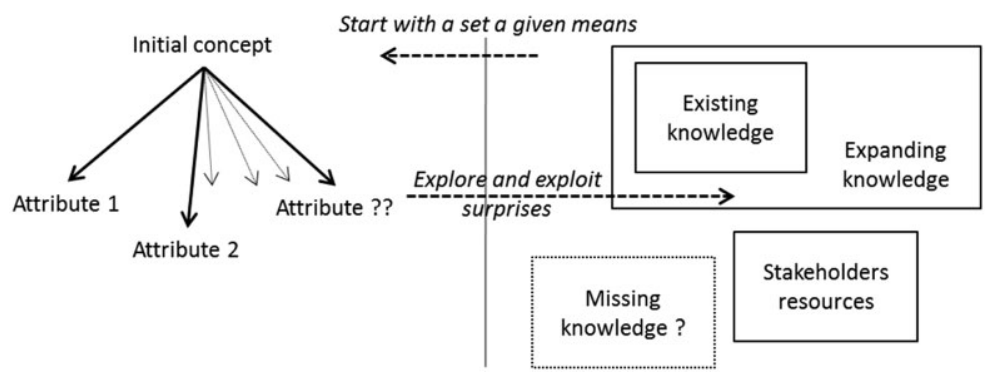

Figure 3. Effectuation through C-K Theory

\section{Method and Material}

\section{Nascent Technology Entrepreneurs at Chalmers University of Technology}

Our present study is based on the analysis of 13 teams of nascent technology entrepreneurs during their first year at Chalmers School of Entrepreneurship (Gothenburg, Sweden). As the programme is based at a technical university, the majority of nascent technology entrepreneurs have a background in engineering or bioscience, with the remainder having expertise in business, law, economics, etc. (Lundqvist \& Williams-Middleton, 2008). The two-year international master of science programme at Chalmers School of Entrepreneurship mainly attracts individuals who aim to have entrepreneurial careers in technologyor bioscience-based start-up firms, or alternatively in established technology-based organizations. The program is action-based (Rasmussen \& Sørheim, 2006), emphasizing learning-by-doing (Cope \& Watts, 2000), with more than half of the participants entering into a venture creation approach (Ollila \& Williams
Middleton, 2011). This approach requires participants to directly engage in bringing to market technology transfer inventions (Lackéus \& Williams Middleton, 2015) through a nine-month incubation period in the final year of the two-year-long programme. We argue that participants attending the programme are nascent technology entrepreneurs, having entrepreneurial intention (particularly those who will enter the venture creation in the second year) based on their application and admission to the programme. They are also well trained in the use of scientific methodology and engineering science, based on their previous education. Historically, 15-20 per cent of the participants continue as entrepreneurs in the technology ventures initiated through the programme (Williams Middleton \& Donnellon, 2014). A vast majority of the graduates engage professionally in technology-based business development at start-ups or in established firms (Berggren et al., 2010; Lundqvist, 2014).

After being given instruction in innovative design theory, 60 nascent technology entrepreneurs, grouped into 13 teams, were given four 
days to apply $\mathrm{C}-\mathrm{K}$ theory and make $\mathrm{C}-\mathrm{K}$ diagrams around a technology platform. They were first introduced to C-K theory and the C-K diagram methodology, both conceptually and through a basic example, in a lecture format supported by complementary reading material. They then worked in their teams over the four days and interacted with an instructor who provided feedback and support. Each team was asked to produce a C-K diagram. $\mathrm{C}-\mathrm{K}$ theory and $\mathrm{C}-\mathrm{K}$ diagrams were not communicated in relation to either mindful deviation, or decision-making logics; nor were the nascent technology entrepreneurs provided specific training in mindful deviation or decision-making logics (causation and effectuation).

C-K theory was applied to a real-life but shelved innovation called Samba Sensor (Figure 4 provides an example $\mathrm{C}-\mathrm{K}$ diagram created by one of the teams). The basic technology behind Samba Sensor is a pressure sensor in which fibre optics allow for pressure measurement, applicable to a variety of interesting areas: for example, monitoring hearts and other body organs, measuring car combustion, or measuring difficult-to-access production environments, such as oil extraction and telecom monitoring. Samba Sensor can be described as a technology platform consisting of eight patents covering basic functions of the sensor as well as different areas of use.

Prior to introduction of C-K theory, the 13 teams had assessed the feasibility of the Samba Sensor innovation. To complete this, the teams were required to delve into the specifics of the patents and make initial choices regarding value and utility of the technology platform. While none of the nascent technology entrepreneurs had previous experience within the particular innovation area, the assessment provided a baseline knowledge of the technology that facilitated exploring possible future opportunities based (to some extent) upon the given technology platform when applying the C-K theory. For 11 of the 13 teams, C-K theory was utilized for developing product concepts and new applications. For the remaining two teams, C-K theory was instead used to explore market opportunities. Figure 4 is an example of the C-K diagrams produced by one of the teams, utilizing C-K theory towards developing a project concept. Figure 4 shows the expansion of both knowledge in the K-space, and pathways in the C-space, as well as the links between the $\mathrm{C}$ and $\mathrm{K}$ spaces.

\section{Data Collection}

We collected our data in two ways: firstly, we analysed the resulting $\mathrm{C}-\mathrm{K}$ diagrams from the application of C-K theory through the frame- work described in relation to Table 1. Secondly, we distributed a questionnaire to all of the nascent technology entrepreneurs, asking questions about their experience of applying the C-K theory. The questionnaire had a $45 \%$ (27 of 60) response rate.

\section{Data Analysis: A Combined Quantitative and Qualitative Approach}

Each team produced a C-K diagram. The 13 $\mathrm{C}-\mathrm{K}$ diagrams were then scored by two raters independently. To do so, the raters used the interpretation of the five principles of causation and effectuation based upon the analytical framework presented in Table 1. For each C-K diagram, the raters had to score the $\mathrm{C}-\mathrm{K}$ diagram according to the format presented in Table 2. Therefore, each diagram received a coupled score, one reflecting the use of causal logic, one reflecting the use of effectual logic. For example, if a team was seen to map both spaces (=1 effectual score), explore different alternatives and build on value of the link between $\mathrm{C}$ and $\mathrm{K}$ (=1 effectual score), map the unknown missing knowledge and the unknown paths (= 1 effectual score), have no disruptive concept (=1 causal score), and present extensive $\mathrm{K}$ mapping (=1 causal score), they would receive a coupled score of $(2,3)$ : a causation score of 2 and an effectuation score of 3 . The ratings displayed satisfactory inter-rater correlation $(r=0.92)$. There is considerable co-variation among both five factors determining causation and the five factors capturing effectuation, but arguably not between the two groups of factors. The factors are thus only helping to detect occurrence of a logic and are only indicative of the magnitude of a logic used. An example scoring based on the team example $\mathrm{C}-\mathrm{K}$ diagram provided in Figure 4 is presented in Table 3.

To identify how the nascent technology entrepreneurs perceived their use of causation and effectuation more in hindsight, the questionnaire included both open-ended questions, as well as one multiple-part Likert-scale question (see Appendix). The first three openended questions addressed how the nascent technology entrepreneur generally comprehended C-K theory related to the Samba Sensor case, in order to qualify that the response to the final questions were not impeded by the use of C-K theory itself. The fourth question addressed the nascent technology entrepreneur's own interpretation of their performance in applying C-K theory towards exploring the potential pathways of the technology. The fifth and final question utilized a Likert-scale format, designed to investigate perceived use of $\mathrm{C}-\mathrm{K}$ theory in terms of six 


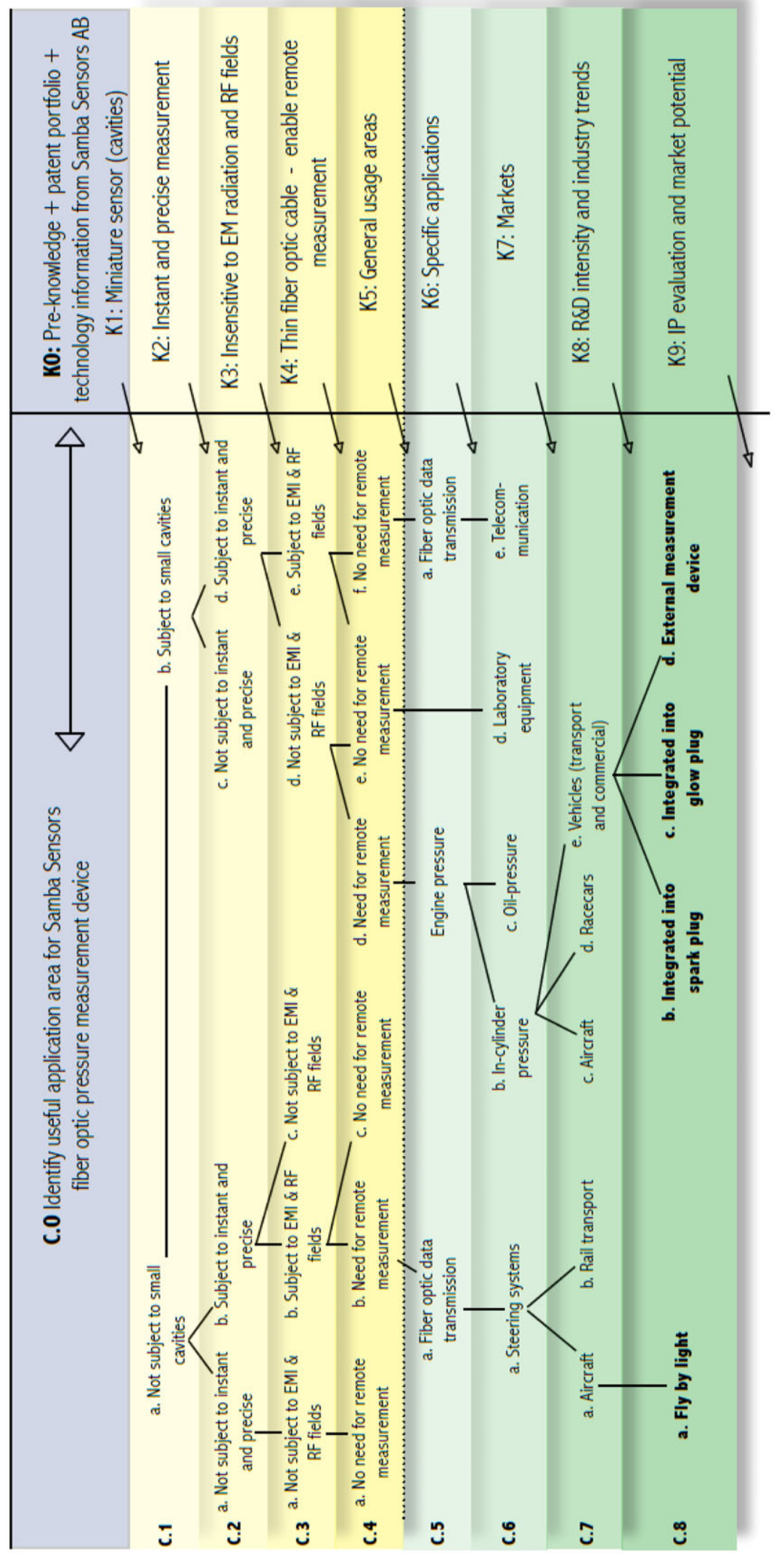

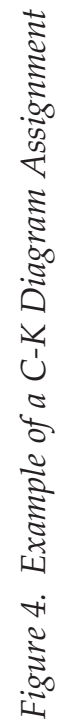


Table 2. Analytical Framework for a C-K Diagram

\begin{tabular}{lclc}
\hline Causal logic & No/Yes & \multicolumn{1}{c}{ Effectual logic } & No/Yes \\
\hline $\begin{array}{l}\text { Map the knowledge space } \\
\begin{array}{l}\text { Explore one linear path and } \\
\text { the value it holds (explore one } \\
\text { path in C) }\end{array}\end{array}$ & $0 / 1$ & $\begin{array}{l}\text { Map both spaces } \\
\text { Explore different alternatives and build } \\
\text { on value of the link between C and K } \\
\text { (capability to shift design path) } \\
\quad \text { the existing alternatives }\end{array}$ & $0 / 1$ \\
$\begin{array}{l}\text { No disruptive concept } \\
\begin{array}{l}\text { Control and anticipation of } \\
\text { all possible scenarios/ }\end{array}\end{array}$ & $0 / 1$ & $\begin{array}{l}\text { Map the unknown missing knowledge } \\
\text { and the unknown paths }\end{array}$ & $0 / 1$ \\
$\begin{array}{l}\text { Extensive K mapping } \\
\text { Total }\end{array}$ & $0 / 1$ & $\begin{array}{l}\text { Disruptive concept } \\
\text { Robustness }\end{array}$ & $0 / 1$ \\
\hline
\end{tabular}

Table 3. Example Data Analysis of a C-K Diagram

\begin{tabular}{|c|c|c|c|}
\hline Causal logic & No/Yes & Effectual logic & No/Yes \\
\hline Map the knowledge space & 0 & Map both spaces & 1 \\
\hline $\begin{array}{l}\text { Explore one linear path and } \\
\text { the value it holds (explore one } \\
\text { path in } C \text { ) }\end{array}$ & 0 & $\begin{array}{l}\text { Explore different alternatives and build } \\
\text { on value of the link between } \mathrm{C} \text { and } \mathrm{K} \\
\text { (capability to shift design path) }\end{array}$ & 1 \\
\hline $\begin{array}{l}\text { Map the missing knowledge and } \\
\text { the existing alternatives }\end{array}$ & 1 & $\begin{array}{l}\text { Map the unknown missing knowledge } \\
\text { and the unknown paths }\end{array}$ & 1 \\
\hline No disruptive concept & 0 & Disruptive concept & 1 \\
\hline $\begin{array}{l}\text { Control and anticipation of } \\
\text { all possible scenarios / } \\
\text { Extensive K mapping }\end{array}$ & 0 & Robustness & 0 \\
\hline Total & 1 & Total & 4 \\
\hline
\end{tabular}

different orientations: (a) action-orientation, (b) goal-orientation, (c) process-orientation, (d) product-orientation, (e) actor-orientation and (f) reflexively. Items (a), (c) and (e) are seen to align with effectuation principles while items (b), (d) and (f) align with causation principles. Previous studies have applied similar data collection methods in order to assess the use of causal and effectual logics in decision making towards new venture or technological development (Chandler et al., 2011; Brettel et al., 2012; Harms \& Schiele, 2012). Furthermore, the Likert-scale question mirrors a study conducted by Brettel et al. (2012), addressing the use of causal and effectual logics relative to $R \& D$ project performance, as our respondents are, like the Brettel et al. study, asked to evaluate preference towards causal or effectual logics through a Likert scale format, as well as subjective performance evaluation. As for the first part of the data analysis, this resulted in coding each participant responses based on the Likert-scale questions. Indeed, the responses to parts (a)-(f) of the final question in the questionnaire were utilized to establish a coupled score (effectual score, causal score), where the effectual score was the mean of the answers given in items (a), (c) and (e), while the mean of the score given in (b), (d) and (f) provided the causal score.

\section{Results}

\section{Coding C-K Diagrams and Evaluating} Causation and Effectuation

The 13 teams delivered analyses utilizing C-K diagrams. For each team/C-K diagram, a co-ordinate is generated from the coupled score (effectual score, causal score), with 


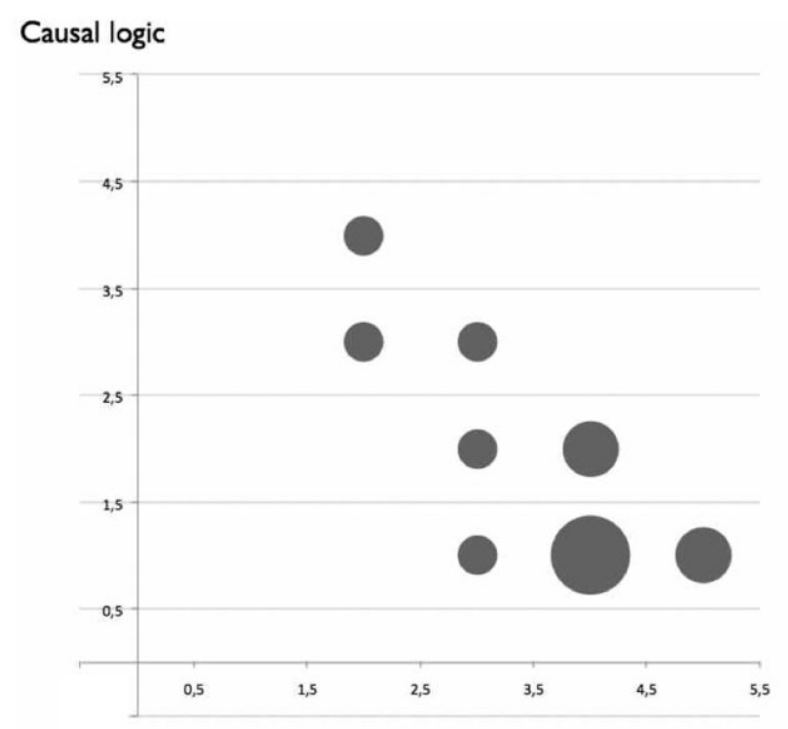

Effectual logic

Figure 5. Primary Analysis of the Outcomes of Applying Design Theory-Driven Methodology: Effectual-Causal Coupled Score

minimum possible score of zero and maximum possible score of five (using the scoring system from Table 2). The 13 coupled scores were then compiled to illustrate the overall causal and effectual distribution across all 13 teams (Figure 5). In Figure 5, the $x$-axis represents the effectual score and the $y$-axis represents the causal score. The axes range from zero to five to illustrate the score generated for each team through the analytical framework (Table 2), with the coupled score establishing a co-ordinate relative to the $\mathrm{x}$ and $y$ axes. The size of the dots is correlated with the number of teams that generated the same coupled score, such that a smaller circle would represent fewer teams with the same score, and a larger circle would represent a larger number of teams with the same score.

Figure 5 shows that in applying C-K diagrams to the sensor technology, the actions of the nascent technology entrepreneurs can be interpreted as combining causation and effectuation, but with a greater emphasis on the use of effectual decision making.

\section{Perception of Use}

The responses to the final question in the questionnaire establish a coupled score (effectual score, causal score), generating a co-ordinate, shown in Figure 6. Figure 6 compares the respondent's own perceived use of causal and effectual decision making, as determined by the coupled score. The same representation applied in Figure 5 is also used in Figure 6; thus, again the $x$-axis represents the effectual score and the $y$-axis represents the causal score, with the coupled score of each respondent generating a co-ordinate presented in the figure. Again, similar to the format of Figure 5, the size of the dots in Figure 6 is correlated with the number of respondents that were coded with the same coupled score.

Figure 6 illustrates that respondents tended to interpret their perceived use of C-K diagrams towards decision making as causally oriented more than effectually oriented.

In comparison, Figures 5 and 6 differ as regards occurrence of causation and effectuation. The questionnaire, which was answered in hindsight (Figure 6), indicates mainly use of causal logic, whereas use of effectual logic is seen to occur more extensively when interpreting the use of C-K diagrams (Figure 5). These results thus suggest a gap between the decision making actually done (being more effectual) and how the nascent technology entrepreneurs in hindsight perceive their own decision making (stated in more causal terms).

\section{Discussion and Conclusions}

The purpose of this article is to explore mindful deviation in technology entrepreneurship as decision making combining causal and effectual logics. First, the discussion will investigate the relevance of a decision-making 


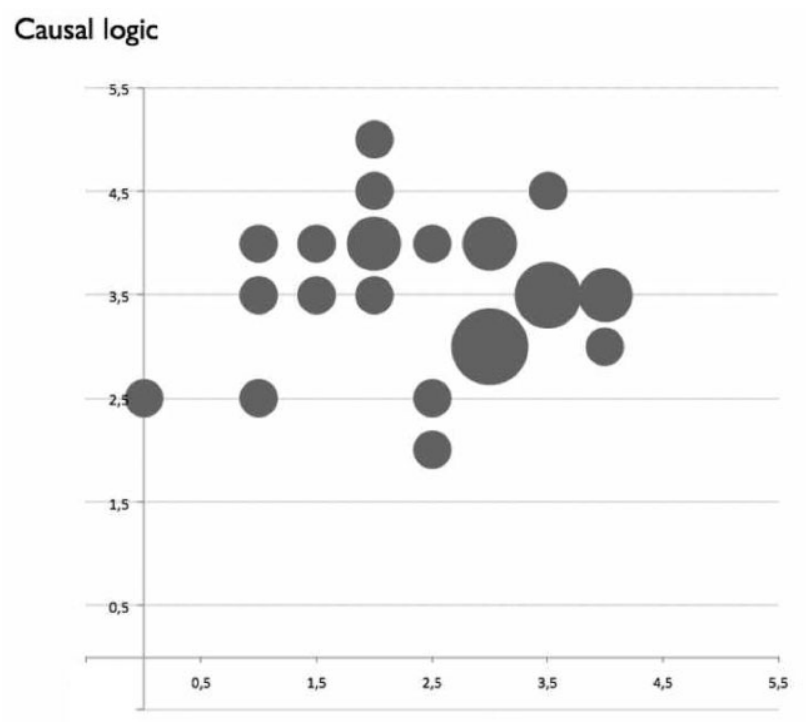

Effectual logic

Figure 6. Supporting Analysis of the Outcomes of Applying Design Theory-Driven Methodology: Perception of Use

approach. Following this, four aspects related to the occurrence of effectual and causal logic will be analysed.

Previous studies into technology entrepreneurship basically have understood earlystage deviation into new opportunities as a discrete creative event and not as a decisionmaking process. Prior knowledge of an area (Shane, 2000) as well strong patternrecognition capabilities (Baron, 2006) are identified factors behind successful opportunity recognition. Through $\mathrm{C}-\mathrm{K}$ design theory applied by 13 teams of nascent technology entrepreneurs upon the same innovation, a method for detecting decision making is introduced. Even though prior knowledge among the 13 teams can be considered moderate, the majority are still able to deviate substantially from their original platform technology into a variety of different product concepts. This deviation is also clearly traceable through the C-K diagrams, in which different concepts are logically interrelated in the C-space while knowledge expansions occur in the K-space. It can thus be concluded that deviation in earlystage technology entrepreneurship can be characterized as a decision-making process engaging a team (thus being collective) with moderate prior knowledge, rather than as something singular, individualistic and depending upon prior knowledge.

Given, the exploratory and experimental character of the study, there are some limitations to this main conclusion. Firstly, although the nascent entrepreneurs were asked both for
C-K maps and written accounts around the process, it is not possible to fully determine how much these delivered outputs actually represent the process and how much they are after-rationalizations of something that might have occurred more individualistically and singularly. Secondly, while the concept of mindful deviation comes from entrepreneurs arguing for and legitimizing a path-breaking solution, the current study does not take into account any subsequent progress and realization of a chosen opportunity. It merely reports that C-K diagrams indicate use of decision making during an early opportunityrecognizing stage. However, given these limitations and the obvious need for further studies, the richness and variety found through applying C-K diagrams in early-stage technology entrepreneurship does suggest that a more singular, individualistic and discovery-oriented (rather than a collective decision-making-oriented) view on technology entrepreneurship can be questioned.

\section{Effectuation Occurring among Nascent Entrepreneurs}

Previous research into effectuation associates effectual logic with experienced entrepreneurs (Sarasvathy, 2001; Read and Sarasvathy, 2005; Dew etal., 2009). This study shows that nascent entrepreneurs also use effectual logic. Whether this is due to the application of C-K theory, or whether this would have been the case regardless of the method used, is difficult 
to say. However, our study suggests that effectual logic should subsequently be associated not only with experience and seniority. Rather, effectual logic can also occur - either naturally or induced through method - among individuals lacking entrepreneurial experience. This arguably widens substantially 'the population of effectuators', while demystifying this type of decision making as not depending significantly upon expertise and certain experiences.

\section{Hindsight Bias Disguises Effectuation}

Results from the questionnaire indicate that use of effectual logic is more difficult to detect in hindsight. Whether this is due to the nascent technology entrepreneur lacking sufficient skill, experience or language to appreciate an effectual logic, or whether such hindsight bias always would occur, is not possible to determine through the current study. Nevertheless, this differentiation between the application versus perceived use of effectual logic is not addressed in previous studies of effectuation (e.g., Dew et al., 2009). There is thus strong reason to continue exploring more interactive (rather than ex post) measurement of effectual logic if we want to capture its occurrence and relevance. Interactive measurement may also help to avoid a hindsight bias, through which humans simplify and rationalize in order to make sense of a more complex and fluid experience (Kahneman \& Riepe, 1998). In conclusion, our study suggests that effectuation occurs much more in action than is possible to detect in hindsight, adding to the previous conclusion that this decision-making logic should be demystified and not solely associated with experts or previous experience.

\section{Expanding Mindful Deviation into Opportunity Recognition}

The tracing of decision making through C-K diagrams adds to our understanding of mindful deviation. The concept of mindful deviation has been associated with later stages of technology entrepreneurship, where the need to convince others to join or buy into a chosen novel path is essential (Garud \& Karnøe, 2001a). The current study expands mindfulness into the early concept-generative phase of technology entrepreneurship, where mindfulness was observed as effectual and causal decision making. So, while mindful deviation has been more readily associated with individual technology entrepreneurs communicating to and convincing others, the current study instead emphasizes the inclusion of persons into a more collective and open-ended decision making, which precedes any subsequent and perhaps more persuasive process. Although this is a shift in perspective (from convincing to making decisions) and includes earlier stages (opportunity recognition), we propose that the concept of mindful deviation remains highly relevant and is even enriched through the current study. Future studies into technology entrepreneurship as a process ought to benefit from focusing more on the process of collective and mindful articulation, whether for explorative (decision making) or more exploitative (convincing and influencing) purposes.

\section{Mindful Deviation as Combining Effectuation and Causation}

Finally, the interpretation of the C-K diagrams relative to effectuation and causation can increase our understanding of how the two logics can be combined. The factors used to define effectuation and causation (Table 1) arguably imply that path deviation requires effectuation. Effectuation deals with starting with means while keeping ends open, as well as allowing contingencies to trigger imaginary rethinking. Causation, on the other hand, assumes ends and objectives to be fixed or predetermined. Hence, it is perhaps not surprising to find more effectual logic occurring in the $\mathrm{C}-\mathrm{K}$ diagrams. However, without any causal logic illustrated in the $\mathrm{C}-\mathrm{K}$ diagrams, the notion of mindfulness, including being able to make and communicate conscious decisions, would be hampered due to lack of consequential reasoning and inability to compare different choices. Combining effectuation and causation then comes close to the type of strategic decision making proposed as 'the science of muddling through' (Lindblom, 1959,1979 ) or 'logical incrementalism' (Quinn, 1978). As far as we are aware, early-stage opportunity recognition has not previously been associated with such strategy-making concepts. Rather early-stage opportunity recognition has been said to be reliant upon appreciation of the insightfulness of experts with certain pattern-recognition capabilities. In essence, the combination of causal and effectual thinking displayed by all 13 teams helped create a more holistic map in which consequential paths as well as path deviations are included.

The variety of application ideas traced using C-K diagrams should thus be ascribed not only to the use of effectuation, but rather to the combination of both causation and effectuation. For example, sometimes the teams converged on a goal, and then elaborated on the goal further. Other times, it is obvious that new concepts emerged through effectual decision making and were then translated as a goal 
once identified. In conclusion, the combination of effectuation and causation reflects that (nascent) technology entrepreneurs are required to address both existing technological paths and novel entrepreneurial developments, and that they benefit from decision-making processes more similar to strategy making than to singular events of individual insightfulness.

\section{Limitations and Next Steps}

There are several limitations to our study. The current study is local and contextual and requires further validation to substantiate claims that effectual decision making is used by early-stage technology entrepreneurs (Chandler et al., 2011; Perry, Chandler \& Markova, 2011). Our study of the decisionmaking behaviour of (nascent) technology entrepreneurs is, through the first level of analysis, based on coding the outcome of four days of work on a design theory-based interpretation of the two types of decision making (causal and effectual). This experimental setting is of course limited in time as well as in realism (the entrepreneurs knew this was a shelved innovation, and thus not completely 'real'). Nevertheless, the setting is illustrative of early-stage technology entrepreneurship, mirroring initiation of venture creation. The interpretative means for determining causal and effectual logics, the second level of analysis, while based on previous work, could also benefit from further testing.

A second limitation is the lack of a control group (such as more traditional engineers, consultants, etc.). The study could potentially benefit from having a control group to determine if the participants in the current study, as a population, have a specific mind-set which might bias their application and/or perception one way or another. The teams were mostly hybrids, with team members having engineering or business degree backgrounds. However, our study has traced mindful deviation in a population intending to (at least) become entrepreneurial (if not entrepreneurs). Studying groups lacking such ambition may not provide relevant insight into entrepreneurial decision-making processes, as these groups might lack the agency emphasized in the existing literature.

Our study was conducted on technology entrepreneurship students due to the easy access to this specific population. However, such a selection in our data sample might not reflect both the actions and the perception of these actions of more mature and experienced technology entrepreneurs. Yet it allows elaboration on future hypotheses for the current understanding of nascent technology entrepreneurs. Facilitating traceable conscious decision-making processes of technology entrepreneurs may also allow us to increase general understanding of entrepreneurial cognition, as explored in the work of Mitchell et al. (2007).

Finally, although the current study indicates behavioural preference towards effectuation and cognitive preference towards causation, this should not automatically favour one at the expense of the other. Rather, C-K theory, through C-K diagrams, seems to offer a valuable tool to further explore actual entrepreneurial behaviour as well as entrepreneurial perception and identity. The current study shows that even a simulated setting can offer some insights. Further studies could look into use of C-K diagrams more longitudinally as well as related to more real-life entrepreneurship situations.

\section{References}

Agogué, M., Hooge, S., Arnoux, F. and Brown, I. (2014) Introduction to C-K Theory. Presses des Mines, Paris.

Agogué, M. and Kazakçi, A. (2014) 10 Years of C-K Theory: A Survey on the Academic and Industrial Impacts of a Design Theory. In Chakrabarti, A. and Blessing, L.T. (eds.), An Anthology of Theories and Models of Design. Springer, London, pp. 219 36.

Bailetti, T. (2012) Technology Entrepreneurship: Overview, Definition, and Distinctive Aspects. Technology Innovation Management Review, 2, 5-12.

Baron, R.A. (2006) Opportunity Recognition as Pattern Recognition: How Entrepreneurs 'Connect the Dots' to Identify New Business Opportunities. Academy of Management Perspectives, 20, 104-19.

Beckman, C.M., Eisenhardt, K., Kotha, S., Meyer, A. and Rajagopalan, N. (2012) The Role of the Entrepreneur in Technology Entrepreneurship. Strategic Entrepreneurship Journal, 6, 203-6.

Berggren, J., Brunnegård, V., Edgar, B., Faxheden, T., Henricson, K., Lundqvist, M., Namousi, D., Norell, L., Rydell, M. and Skarin, M. (2010) Progress Report 2009. Göteborg, Sweden.

Brettel, M., Mauer, R., Engelen, A. and Küpper, D. (2012) Corporate Effectuation: Entrepreneurial Action and Its Impact on R\&D Project Performance. Journal of Business Venturing, 27, 167-84.

Chakrabarti, A. and Blessing, L.T. (2014) Theories and Models of Design: A Summary of Findings. In Chakrabarti, A. and Blessing, L.T. (eds.), An Anthology of Theories and Models of Design. Springer, London, pp. 1-46.

Chandler, G., Detienne, D., McKelvie, A. and Mumford, T. (2011) Causation and Effectuation Processes: A Validation Study. Journal of Business Venturing, 26, 375-90. 
Cope, J. and Watts, G. (2000) Learning by Doing: An Exploration of Experience, Critical Incidents and Reflection in Entrepreneurial Learning. International Journal of Entrepreneurial Behaviour $\mathcal{E}$ Research, 6, 104-24.

Dew, N., Read, S., Sarasvathy, S.D. and Wiltbank, R. (2009) Effectual versus Predictive Logics in Entrepreneurial Decision-Making: Differences between Experts and Novices. Journal of Business Venturing, 24, 287-309.

Doganova, L. and Eyquem-Renault, M. (2009) What Do Business Models Do? Innovation Devices in Technology Entrepreneurship. Research Policy, 38, 1559-70.

Fisher, G. (2012) Effectuation, Causation, and Bricolage: A Behavioral Comparison of Emerging Theories in Entrepreneurship Research. Entrepreneurship Theory and Practice, 36, 1019-51.

Garud, R., Gehman, J. and Giuliani, A.P. (2014) Contextualizing Entrepreneurial Innovation: A Narrative Perspective. Research Policy, 43, 117788.

Garud, R. and Karnøe, P. (2001a) Path Dependence and Creation. Lawrence Erlbaum Associates, Mahwah, NJ.

Garud, R. and Karnøe, P. (2001b) Path Creation as a Process of Mindful Deviation. In: Garud, R. and Karnøe, P. (eds.), Path Dependence and Creation. Lawrence Erlbaum Associates, Mahwah, NJ.

Garud, R. and Karnøe, P. (2003) Bricolage versus Breakthrough: Distributed and Embedded Agency in Technology Entrepreneurship. Research Policy, 32, 277-300.

Harms, R. and Schiele, H. (2012) Antecedents and Consequences of Effectuation and Causation in the International New Venture Creation Process. Journal of International Entrepreneurship, 10, 95-116.

Hatchuel, A., Le Masson, P. and Weil, B. (2004) CK Theory in Practice: Lessons from Industrial Applications. Proceedings of DESIGN 2004, the 8th International Design Conference, Dubrovnik, Croatia.

Hatchuel, A., Le Masson, P. and Weil, B. (2005) The Development of Science-Based Products: Managing by Design Spaces. Creativity and Innovation Management, 14, 345-54.

Hatchuel, A. and Weil, B. (2009) C-K Design Theory: An Advanced Formulation. Research in Engineering Design, 19, 181-92.

Hatchuel, A., Weil, B. and Le Masson, P. (2013) Towards an Ontology of Design: Lessons from C-K Design Theory and Forcing. Research in Engineering Design, 24, 147-63.

Hooge, S., Agogué, M. and Gillier, T. (2012) A New Methodology for Advanced Engineering Design: Lessons from Experimenting CK Theory Driven Tools. Proceedings of DESIGN 2012, International Design Conference, Dubrovnik, Croatia.

Kahneman, D. and Riepe, M.W. (1998) Aspects of Investor Psychology. The Journal of Portfolio Management, 24, 52-65.

Lackéus, M. and Williams Middleton, K. (2015) Venture Creation Programs: Bridging Entrepreneurship Education and Technology Transfer. Education + Training, 57, 48-73.
Lindblom, C.E. (1959) The Science of 'Muddling Through'. Public Administration Review, 19, 79-88. Lindblom, C.E. (1979) Still Muddling, Not Yet Through. Public Administration Review, 39, 517526.

Lundqvist, M.A. (2014) The Importance of Surrogate Entrepreneurship for Incubated Swedish Technology Ventures. Technovation, 34, 93-100.

Lundqvist, M.A. and Williams-Middleton, K. (2008) Sustainable Wealth Creation beyond Shareholder Value. In Wankel, C. and Stoner, J. (eds.), Innovative Approaches to Global Sustainability. Palgrave Macmillan, New York.

Marvel, M.R. and Lumpkin, G.T. (2007) Technology Entrepreneurs' Human Capital and Its Effects on Innovation Radicalness. Entrepreneurship Theory and Practice, 31, 807-28.

Mitchell, R.K., Busenitz, L.W., Bird, B.J., Gaglio, C.M., McMullen, J.S., Morse, E.A. and Smith, J.B. (2007) The Central Question in Entrepreneurial Cognition Research. Entrepreneurship Theory and Practice, 31, 1-27.

Nielsen, S.L. and Lassen, A.H. (2012) Identity in Entrepreneurship Effectuation Theory: A Supplementary Framework. International Entrepreneurship and Management Journal, 8, 373-89.

Obrecht, J.-J. (2011) On the Relevance of the Concept of Entrepreneurial Capabilities. International Journal of Entrepreneurship and Small Business, 13, 107-25.

Ollila, S. and Williams Middleton, K. (2011) The Venture Creation Approach: Integrating Entrepreneurial Education and Incubation at the University. International Journal of Entrepreneurship and Innovation Management, 13, 161-78.

Perry, J.T., Chandler, G.N. and Markova, G. (2011) Entrepreneurial Effectuation: A Review and Suggestions for Future Research. Entrepreneurship Theory and Practice, 36, 1-25.

Quinn, J.B. (1978) Strategic Change: 'Logical Incrementalism'. Sloan Management Review, 20, 7-19.

Rasmussen, E. and Sørheim, R. (2006) Action-Based Entrepreneurship Education. Technovation, 26, 185-94.

Ratinho, T., Harms, R. and Walsh, S. (2015) Structuring the Technology Entrepreneurship publication landscape: Making sense out of chaos. Technological Forecasting and Social Change, doi.org/10.1016/j.techfore.2015.05.004.

Read, S. and Sarasvathy, S.D. (2005) Knowing What to Do and Doing What You Know: Effectuation as a Form of Entrepreneurial Expertise. Journal of Private Equity, 9, 45-62.

Read, S., Sarasvathy, S.D., Dew, N., Wiltbank, R. and Ohlsson, A.-V. (2011) Effectual Entrepreneurship. Routledge, London.

Sarasvathy, S.D. (2001) Causation and Effectuation: Toward a Theoretical Shift from Economic Inevitability to Entrepreneurial Contingency. Academy of Management Review, 26, 243-63.

Sarasvathy, S.D. (2003) Entrepreneurship as a Science of the Artificial. Journal of Economic Psychology, 24, 203-20.

Sarasvathy, S.D. (2008) Effectuation: Elements of Entrepreneurial Expertise. Edward Elgar, Cheltenham. 
Sarasvathy, S.D. and Dew, N. (2005) Entrepreneurial Logics for a Technology of Foolishness. Scandinavian Journal of Management, 21, 385-406.

Sarasvathy, S.D., Dew, N., Read, S. and Wiltbank, R. (2008) Designing Organizations that Design Environments: Lessons from Entrepreneurial Expertise. Organization Studies, 29, 331-50.

Sarasvathy, S.D. and Venkataraman, S. (2011) Entrepreneurship as Method: Open Questions for an Entrepreneurial Future. Entrepreneurship Theory and Practice, 35, 113-35.

Shane, S. (2000) Prior Knowledge and the Discovery of Entrepreneurial Opportunities. Organization Science, 11, 448-69.

Shane, S. and Venkataraman, S. (2000) The Promise of Entrepreneurship as a Field of Research. The Academy of Management Review, 25, 217-26.

Shane, S. and Venkataraman, S. (2003) Guest Editors' Introduction to the Special Issue on Technology Entrepreneurship. Research Policy, 32, 181-4.

Sharif Ullah, A., Rashid, M.M. and Tamaki, J.I. (2012) On Some Unique Features of C-K Theory of Design. CIRP Journal of Manufacturing Science and Technology, 5, 55-66.

Simon, H.A. (1996) The Sciences of the Artificial. MIT Press, Cambridge, MA.

Sydow, J., Schreyögg, G. and Koch, J. (2009) Organizational Path Dependence: Opening the Black Box. Academy of Management Review, 34, 689-709.

Van Burg, E., Romme, A.G.L., Gilsing, V.A. and Reymen, I.M.M.J. (2008) Creating University Spin-Offs: A Science-Based Design Perspective. Journal of Product Innovation Management, 25, 11428.

Williams Middleton, K. and Donnellon, A. (2014) Personalizing Entrepreneurial Learning: A Pedagogy for Facilitating the Know Why. Entrepreneurship Research Journal, 4, 167-204.

Wiltbank, R., Dew, N., Read, S. and Sarasvathy, S.D. (2006) What to Do Next? The Case for NonPredictive Strategy. Strategic Management Journal, 27, 981-98.

Marine Agogué (marine.agogue@hec.ca) is an assistant professor in innovation management at HEC Montréal and is a member of the Chair Design Theory and Methods for Innovation at Mines ParisTech. She works on fixation effect in creativity and on cognitive bias in innovation. Her work has been published in journals such as Journal of Creative Behavior, International Journal of Innovation Management and Technology Analysis $\mathcal{E}$ Strategic Management.
Mats Lundqvist (mats.lundqvist@ chalmers.se) is Professor in Entrepreneurship at Chalmers University of Technology, as well as the director and co-founder (in 1997) of Chalmers School of Entrepreneurship, the top-ranked entrepreneurship institution in Sweden. Research interests include university entrepreneurship, academic entrepreneurship, incubation practice, action-based entrepreneurship education as well as institutional transformations. His work has been published in, for example, Research Policy, Science and Public Policy, RED Management and Technovation.

Karen Williams Middleton (karen .williams@chalmers.se) is an associate professor in entrepreneurship at Chalmers University of Technology, with research interests in the areas of nascent entrepreneurship, entrepreneurial identity and behaviour, entrepreneurial learning and education, and university entrepreneurship. Her work has been published in, for example, Journal of Small Business and Enterprise Development, International Journal of Entrepreneurial Behaviour Research and International Journal of Entrepreneurship and Innovation Management.

\section{Appendix}

Question 1. Was C-K theory useful for the Samba Sensor case?

Question 2. Was C-K theory easy to understand?

Question 3. Was the amount of introduction to C-K theory sufficient?

Question 4. Describe in your own words how you applied C-K theory.

Question 5. On a scale of 1(low) to 5 (high), how did you apply C-K theory, in terms of the following:

a. from an action-oriented perspective

b. from a goal-oriented perspective

c. from a process-oriented perspective

d. from a product/service oriented perspective

e. from an actor-oriented perspective

f. reflexively 